\title{
Research on Electricity Retail Market Design Considering Renewable Energy Storage Resources
}

\author{
Shuo Yin ${ }^{a}$, Xing Chen ${ }^{b}$, Shiqian Wang, Zhe Chai, Man Jin, Xingwu Guo, \\ Yao Lu
}

\author{
State Grid Henan Electric Power Company Economic and Technical Research Institute \\ Zhengzhou, China \\ a411761498@qq.com, b chenxing_11@qq.com
}

\begin{abstract}
This research focus on electricity retail market design considering renewable energy storage resources under the background of the National Development and Reform Commission issuing the policy on establishing and improving the consumption and consumption guarantee of renewable energy power. Renewable energy storage resources are the key consideration in the design of current market mechanism problems. This research shows the investment and construction costs of renewable energy storage resources based on the analysis of the electricity retail market. The research results provide practical reference for electricity retail market players to design power retail packages that meet clean energy consumption in a diversified and competitive environment.
\end{abstract}

Keywords: New Energy Storage; Electricity Retail Market; Cost Forecast; Renewable Energy Power.

\section{Introduction}

In recent years, relevant policy documents have been issued successively to connect the power sales company with the retail user group. The successful retail market is regarded as the construction of power market and the implementation of quota system in the future. It can be seen that power selling companies are in the retail market. Stabilize the fluctuation of various transaction prices and encourage retail users to consume clean products. The role of energy will directly affect the completion of the task of renewable energy consumption situation. Retail markets in some countries such as the UK, Australia and Singapore. The construction of the market started earlier and has its own characteristics, which is of great significance to China retail market. The design is of great reference significance.

\section{Analysis of the Electricity Retail Market Design}

Introduced to form the coexistence of medium and long-term trading and spot trading, and the integration of conventional energy. The situation of joint participation of clean energy in the transaction makes the transaction varieties appear to be competitive. The characteristics of forking and diversification bring new challenges to the mechanism construction of power retail market. In line with the top-level design idea of the power market, consider the consumption of renewable energy quota. According to the actual situation of the task, this paper analysed the current operation process of the retail market.

\subsection{Investment and Construction Costs of Renewable Energy Storage Resources}

Retail packages are rigid and quota distribution in the retail market is not considered, Study and establish a flexible and efficient retail market trading mechanism. Under the new trading mechanism, the use of Hamilton function is introduced. Retail package designer for calculating the coupling of quota index and retail price Law. This method can be used according to the renewable energy storage of retail users. Retail packages are designed to fully stimulate the demand of different proportions and retail prices. 
Table 1. Cost Composition Analysis of Energy Storage

\begin{tabular}{|c|c|c|}
\hline \multicolumn{2}{|c|}{ Energy Storage System Cost } & Ratio \\
\hline \multirow{3}{*}{\begin{tabular}{c} 
Construction Cost \\
\cline { 2 - 3 }
\end{tabular}} & Battery Cost & $49.8 \%$ \\
\cline { 2 - 3 } & Battery Supporting Facilities Cost & $15.8 \%$ \\
\hline \multicolumn{2}{|c|}{ Operation and Maintenance Cost } & $17.4 \%$ \\
\hline Financial Cost & $1.6 \%$ \\
\hline \multicolumn{2}{|c|}{ Total } & $100 \%$ \\
\hline
\end{tabular}

Table 1 shows the cost composition analysis of energy storage. The purchase cost of these equipment constitutes the equipment installation cost.

\subsection{Operation Costs of Renewable Energy Storage Resources}

Summarize the retail market mechanism setting in Europe and the United States, and its capital. The flow direction of power flow and power flow is unified, that is, who pays and who buys electric energy. Whoever receives the money provides electric energy [1-2]. Singapore power, which belongs to Asia. Taking the retail market as an example, like China, according to the annual power consumption of users. Users who do not have the qualification of optional power supply. Unlike the top-level design of China's power market, Singapore power Electricity charge in retail market. According to different choices of power users, user payment methods are also different: If you choose to purchase electricity from a retailer, the power supply fee, service fee, transmission and distribution fee will be charged. The electricity fee and the collected tax are paid to the retailer together, and then the electricity is zero.

\subsection{Value of Renewable Energy Storage Resources}

The seller settles with the market service provider on its behalf; If the user selects from the city. If you purchase electricity from the field service provider, you can pay the above fees to the city. Field service provider shall complete the settlement of various expenses by its agent. And for power retailers, when charging all fees to power users, some fees are collected on behalf of the market service provider, and there is a certain risk of arrears. Therefore, the trading rules of the electricity retail market require retailers to report to the market. The field service provider shall pay a deposit to avoid the possibility of market service providers. The difference between China's power market construction and foreign countries is that the power grid company acts as the intermediate node of electricity charge. The power grid company pays the power generation cost to the power generation enterprise. All provinces in China take into account the retail trade with the participation of power selling companies. Market construction, but the degree of liberalization of power sales companies in various provinces is different. Some provinces have allowed power selling companies to participate in market-oriented transactions and initially established. It is mainly based on power sales companies acting as agents for retail users to purchase power, and virtual power plants. The retail market of polymers such as energy storage providers in individual provinces.

Based on the retail market composed of households, relevant documents and specifications shall be issued. Construction of power retail market has changed the original power sales company. The method of negotiating retail price and service fee with retail users becomes retail. The user negotiates with the power selling company to select the retail package, which shortens the settlement week. During this period, the behaviour of retail market has been standardized. Shanxi supports the development of power sales company. Data connection between the third-party retail trading platform and the trading center platform. The power company manages its agent retail users through its own platform to broaden. The scope of management of retail users by power sales companies is discussed. Yunnan is handed over by the provincial government. E-commerce center has established a unified retail trading platform to support multi-agent relationship.

The cost composition ratio of each part of the new energy storage is shown in Figure 1. 


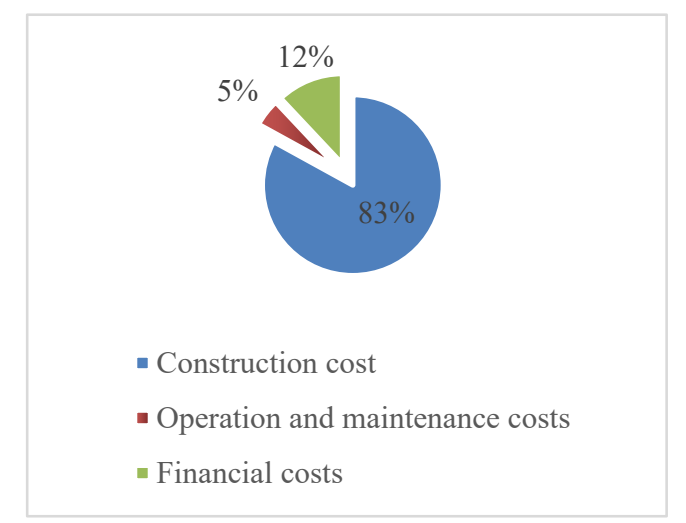

Figure 1. The cost proportion of each part of the energy storage system (data sources: Bloomberg $\mathrm{NEF}$ )

\section{Renewable Energy Storage Resources}

\subsection{Renewable Energy Storage Resources Cost Estimation Model}

Management, multiple income distribution mode selection and other functions. Develop the research on the mechanism of virtual power plant by aggregating power generation, storage, power consumption. Such market entities realize peak shaving and valley filling to reduce frequent startup of generator units. With the introduction of the document, some retail markets can no longer adapt to the new guidance. It is urgent to develop a retail market suitable for the national top-level design. The diversified needs of power retail users is to guide the competitiveness of power retail market. The Renewable Energy Storage Resources issued the LCOE formula, as shown in equation (1), by calculating project operations Life cycle cost and power generation during operation cycle, and discount the cost and power generation of the whole operation cycle according to a fixed discount rate to obtain the calculation formula of the levelized electricity cost.

$$
\operatorname{LCOE}=\frac{\left[I_{0}+\sum_{n=1}^{N} O \& M_{n}\right]}{\sum_{n=1}^{N} G_{n}}
$$

In the formula: Renewable energy quota system indicators will stimulate retail users to choose electricity sales with price and quota index advantages. The company is also the key to affecting the power selling company and the whole retail market factor [3]. With the increasingly mature construction of China's power market, it will form coordinated development of spot market and medium and long-term market, renewable energy and constant energy.

The above-mentioned LCOE calculation model has not yet considered the time value of money. In response to this problem, this article comprehensively considers its technical characteristics and service life from the perspective of the full life cycle of energy storage projects, and introduces the discount rate of funds to consider the time value of money, as shown in formula (2).

$$
\mathrm{LCOE}=\frac{\left[\mathrm{I}_{0}+\sum_{\mathrm{n}=1}^{N} \frac{O \& M_{n}}{(1+\mathrm{i})^{\mathrm{n}}}\right]}{\sum_{\mathrm{n}=1}^{\mathrm{N}} \frac{\mathrm{G}_{\mathrm{n}}}{(1+\mathrm{i})^{\mathrm{n}}}}
$$

In the formula: $\mathrm{V}$ represents the residual value of the project, and i represents the discount rate of funds.

In formula (2), The sales package is relatively single, which is not conducive to stimulating market vitality. To solve the above problems, a set of electric power system suitable for the top-level design 
of China's power market is designed. Strengthen the retail trading mechanism of the market and change the existing trading mechanism of wholesale side and retail side. Easy mechanism to provide mechanism guarantee for the establishment of flexible and efficient retail market. Based on the model above, Table 2 shows the cost changes analysis of wind power storage.

Table 2. Cost Changes Analysis of Wind Power Storage

\begin{tabular}{|c|c|c|c|}
\hline Wind Power & $\begin{array}{c}\text { Unit cost of wind power } \\
\text { project }\end{array}$ & Cost increase (\%) & Generation cost (Yuan/MWh) \\
\hline Latest Bid & 4264.19 & 10.13 & 243.67 \\
\hline $10 \%$ Storage & 4564.48 & 8.51 & 264.41 \\
\hline $20 \%$ Storage & 4864.77 & 17.03 & 285.16 \\
\hline
\end{tabular}

\subsection{New Renewable Energy Storage Resources Cost Prediction Model}

When marketization is not established, power grid enterprises undertake transmission, distribution and sales business. The connection between various businesses belongs to the internal work of the power grid company. After the reform, the internal workflow needs to be divided into different market entities. The design of working mechanism needs to be changed. In order to adapt to the marketoriented reform, the design of wholesale side transaction mechanism needs to be solved [4].

The meter ownership belongs to the power grid company and has established an automatic system. The electricity market construction mode of collecting electricity charges will cause a lot of duplication. Cost is not applicable to China's national conditions and practical conditions. The system design is that independent power trading institutions are responsible for market-oriented trading. Companies, power grid companies and other market entities issue settlement documents as market documents. The basis for the settlement of chemical electricity and electricity charges.

The original model of the learning curve can be expressed by the following formula:

$$
Y=a X^{b}
$$

In the formula: $\mathrm{Y}$ is the unit cost of the product; $\mathrm{a}$ is the unit cost of the first product; $\mathrm{X}$ is the cumulative output of the product; $\mathrm{b}$ is the learning rate index, $0 \leq b \leq 1$.

Taking the logarithm of both sides of the learning curve equation can be converted into a straight line form. Specific steps are as follows:

(1) Data collection. Collect the output and cost of each time period according to a specific time period (using output as the standard).

(2) Data processing. Calculate the unit cost under different cumulative production levels and take the logarithm.

(3) Regression analysis. Perform regression analysis on the dependent variable and independent variable to get the regression equation.

In addition to selling electricity to customers who do not have the right of independent choice, it is also required to have the right of independent choice. Option customers provide market support services in the following two cases. Customers are allowed to supply electricity to the power wholesale market indirectly through new energy services. First, when customers with independent choice are unable or no longer willing to purchase electricity from other power retailers or wholesale markets; Second, when power retailers cannot refuse to sell electricity to customers for any reason. In the mode of power purchase in the power generation market, customers need to bear the price wave of the power wholesale market. Under the institutional framework of controlling the middle and liberalizing both ends, power retail reform. Reforming is the key content of this round of power reform in China. The market is still partially liberalized. Learning from the model is conducive to provide reference for domestic reform and exploration.

With the partial liberalization of the power retail market, the marketing business has gradually changed from companies under vertical integration are divided into distribution operators, power 
retailers and other cities. The members of the market share the responsibility to ensure a smooth transition and compete with other marketing businesses. In other words, minimum guarantee services, metering services and settlement services are usually in the newly entered power market [5]. Retailers do not participate in the undertaking until they have developed to a certain extent. The distribution network operator shall be responsible for the designation, but the measurement data shall be provided to the customer in a timely manner.

The cost learning curve can be expressed as the following form:

$$
C\left(x_{t}, y_{t}\right)=C\left(x_{0}, y_{0}\right)\left(\frac{x_{t}}{x_{0}}\right)^{-\alpha}\left(\frac{y_{t}}{y_{0}}\right)^{-\beta}
$$

Power retailers and distribution network operators can provide settlement services. In the case of partial liberalization of power retail, power retailers and power rationing. Companies can charge end customers, but the charging content will be different, which depends on the choice of charging mode by power retailers. In the case of partial liberalization of the power retail market, the minimum guarantee service is general provided by traditional power retailers, when new power retailers break. If it is unable to sell electricity to the original customers due to production and other reasons, the traditional power retailers should raise it in time. Services to enable these end customers to continue to purchase electricity indirectly from the wholesale market.

Based on the steps above, Table 3 shows the cost changes analysis of photovoltaic power storage.

Table 3. Cost Analysis of Photovoltaic Power Storage

\begin{tabular}{|c|c|c|c|}
\hline $\begin{array}{c}\text { Wind } \\
\text { Power }\end{array}$ & $\begin{array}{c}\text { Unit cost of Photovoltaic power } \\
\text { project }\end{array}$ & Cost increase (\%) & Generation cost (Yuan/MWh) \\
\hline Latest Bid & 3700 & 11.39 & 353.13 \\
\hline $\begin{array}{c}10 \% \\
\text { Storage }\end{array}$ & 4012.15 & 9.87 & 348.32 \\
\hline $\begin{array}{c}20 \% \\
\text { Storage }\end{array}$ & 4324.30 & 22.78 & 389.24 \\
\hline
\end{tabular}

\section{Conclusion}

The power grid company shall be responsible for the payment of electricity charges of power generation and retail users. The risk is also borne by the power grid company; The service fee of the power sales company shall be paid by the grid company. The company pays, but the service fee is negative due to the power selling company. In case of, the power grid company shall collect this part of the cost on behalf of the power selling company. If the fee cannot be paid, it shall be transferred by the financial institution according to the transaction contract. The performance of the power selling company and the expenses of power generation enterprises shall be paid by the power grid company. If the power generation enterprise fails to perform the contract, the power generation enterprise shall pay the contract. The price difference in the corresponding spot period, if the power generation enterprise cannot pay the price difference.

\section{References}

[1] Yao Liangzhong, Deng Zhanfeng, Li Jianlin, Zhang Caiping. Progress in large-scale energy storage technology and its application in high-proportion renewable energy and power electronic equipment power systems [J]. Global Energy Internet, 2021, 4(05): 425-426.

[2] Manasseh Obi, S. M. Jensen, Jennifer B. Ferris, Robert B. Bass. Calculation of levelized costs of electricity for various electrical energy storage systems[J]. Renewable and Sustainable Energy Reviews, 2017, 67: 908-920. 
[3] Jaephil Cho, Sookyung Jeong, Youngsik Kim. Commercial and research battery technologies for electrical energy storage applications[J]. Progress in Energy and Combustion Science, 2015, 48:84-101.

[4] Liu Dahe, Han Xiaojuan, Li Jianlin. Economic analysis of cascade battery energy storage based on photovoltaic power station scenarios[J]. Electric Power Engineering Technology, 2017, 36(06): 27-31+77.

[5] Shen Hanming, Yu Xiahuan. Economic analysis of user-side distributed electrochemical energy storage[J]. Zhejiang Electric Power, 2019, 38(05): 50-54. 